\title{
INTERVENSI ORIGAMI BERBASIS EXPERIENTIAL LEARNING TERHADAP PENINGKATAN KEMAMPUAN SPASIAL ANAK USIA DINI
}

\author{
Agnes Victoria $^{1}$, Riana Sahrani ${ }^{2}$, dan Soemiarti Patmonodewo ${ }^{3}$ \\ ${ }^{1}$ Program Studi Magister Psikologi, Universitas Tarumanagara Jakarta \\ Email: vickie.lukman@yahoo.vom \\ ${ }^{2}$ Fakultas Psikologi, Universitas Tarumanagara Jakarta \\ Email: rianas@fpsi.untar.ac.id \\ ${ }^{3}$ Fakultas Psikologi, Universitas Tarumanagara Jakarta \\ Email : soemiartip@fpsi.untar.ac.id
}

\begin{abstract}
ABSTRAK
Penelitian ini bertujuan untuk mengetahui efektivitas intervensi origami berbasis experiential learning dalam meningkatkan kemampuan spasial anak usia dini. Kemampuan spasial merupakan salah satu kemampuan yang diperlukan manusia dalam kehidupan sehari-hari. Kemampuan spasial merupakan aspek dari kognisi yang berkembang sejalan dengan perkembangan kognitif. Kemampuan spasial pada anak berhubungan dengan relasi topologi atau spasial dua arah, seperti atas-bawah, kanan-kiri, depan-belakang. Banyak media yang terbukti dapat meningkatkan kemampuan spasial pada anak, salah satunya adalah origami. Dalam kegiatan origami, anak diajak untuk berpartisipasi aktif agar dapat membuat figur origami. Hal ini juga dibutuhkan dalam metode experiential learning. Experiential learning merupakan proses belajar melalui pengalaman (learning by doing). Dalam metode ini, siswa berpartisipasi aktif dalam sebuah kegiatan, sehingga menghasilkan pengetahuan atau kemampuan yang baru. Penelitian ini merupakan penelitian kuasi eksperimen. Partisipan penelitian berjumlah 3 orang yang merupakan siswa/i kelas K2 TK X dengan karakteristik: (a) usia partiipan antara 5-6 tahun; (b) partisipan sedang menjalani pendidikan di kelas K2 TK X tahun ajaran 2017-2018. Penelitian ini menggunakan desain dalamkelompok, one-group pretest posttest. Peneliti memberikan intervensi origami berbasis experiential learning kepada partisipan penelitian setelah melakukan pre-test dan melakukan post-test terhadap partisipan setelah 8 sesi intervensi diberikan. Hasil dari penelitian ini menunjukkan kemampuan spasial partisipan mengalami peningkatan meskipun pada dimensi yang berbeda. Hasil post-test pada partisipan penelitian menunjukkan intervensi origami berbasis experiential learning meningkatkan kemampuan spasial anak anak usia dini.
\end{abstract}

Kata Kunci: kemampuan spasial, experiential learning, origami, anak usia dini

\begin{abstract}
This study aims to determine the effectiveness of experiential learning-based origami intervention in improving young children's spatial ability. Spatial ability is a fundamental aspect of cognition that develops in line with cognitive development. Spatial ability in children is associated with topological or two-way spatial relations, such as top-bottom, right-left, front-back. Many media are proven to improve spatial abilities in children, one of which is origami. In origami, children are invited to actively participate in order to make origami figures. This is also needed in experiential learning methods. Experiential learning is a process of learning through experience (learning by doing). In this method, students actively participate in an activity, so as to produce new knowledge or abilities. This research is a quasi-experimental research. There were 3 participants who were students of K2 Grade of Kindergarten $X$ with the following characteristics: $(a)$ the age of participants between 5-6 years; (b) participants are undergoing education in K2 grade kindergarten X during 2017-2018 school year. This study uses within-group design, one-group pretest posttest. The researcher gave origami intervention based on experiential learning to the study participants after pre-test, and administered post-test on the participants after 8 sessions of intervention were conducted. The result of this study indicates that the spatial ability of participants had increased, although in different dimensions. The results of post-test on participants showed that origami interventions based on experiential learning improve the spatial abilities of young children.
\end{abstract}

Keywords: spatial ability, experiential learning, origami, early childhood 


\section{PENDAHULUAN \\ Latar Belakang}

Kemampuan spasial merupakan salah satu kemampuan yang diperlukan manusia dalam kehidupan sehari-hari. Meskipun penelitian mengenai kemampuan spasial sudah banyak dilakukan, belum ada pengertian kemampuan spasial yang pasti. Olkun (2003) menilai kemampuan spasial berhubungan dengan ruang. Olkun mengatakan kemampuan spasial merupakan manipulasi mental terhadap sebuah objek dan bagian-bagian objek tersebut dalam dua dimensi serta ruang tiga dimensi.

Banyak penelitian yang telah meneliti hubungan antara kemampuan spasial dengan matematika terutama dalam membahas geometri. Anak dan orang dewasa yang tampil lebih baik dalam tugas-tugas spasial juga tampil lebih baik dalam tes kemampuan matematika (Casey, Nuttall, \& Pezaris, 2001; Delgado \& Prieto, 2004; Geary, Hoard, Byrd-Craven, Nugent, \& Numtee, 2007; Holmes, Adams, \& Hamilton, 2008; McKenzie, Bull, \& Gray, 2003; Rasmussen \& Bisanz, 2005). Cheng dan Mix (2014) mengatakan bahwa mengetahui hubungan antara ruang dan matematika di usia muda merupakan hal yang penting. Beberapa penelitian mengindikasikan intervensi dini dapat mengurangi jarak kegagalan dalam pelajaran matematika (Duncan et al., 2007; Jordan, Kaplan, Ramineni, \& Locuniak, 2009; Klibanoff, Levine, Huttenlocher, Vasilyeva, \& Hedges, 2006; Starkey, Klein, \& Wakeley, 2004).

Meskipun kemampuan spasial penting untuk dikuasai oleh siswa dari jenjang Taman Kanakkanak, beberapa penelitian di Indonesia menunjukkan kemampuan spasial pada anak TK di beberapa daerah di Indonesia masih kurang (Juli, Saparahayuningsih, \& Suprapti, 2014; Wijayaningsih \& Agnesi, 2014; Anita, Risyak, \& Surahman, 2016). Berdasarkan penelitianpenelitian terdahulu, masih banyak siswa Taman Kanak-Kanak (usia 4-6 tahun) yang kesulitan dalam mengenal warna, ukuran, dan nama bentuk-bentuk geometri. Siswa juga mengalami kesulitan dalam menggambarkan objek yang ada di sekitar. Berdasarkan penelitian-penelitan tersebut, masih banyak siswa Taman Kanak-Kanak di Indonesia yang mengalami kesulitan dalam mengelompokan bentuk, menuangkan ide dan merancang bangunan dari bentuk geometri (Juli, 2014; Wijayaningsih \& Agnesi, 2014; Anita, Risyak, \& Surahman, 2016).

Banyak jenis materi yang dapat mengembangkan kemampuan geometri dan pemikiran spasial pada anak. Salah satunya adalah melalui origami. Penelitian yang dilakukan oleh Cakmak, Isiksal, \& Koc (2014) menunjukkan origami-based instruction merupakan salah satu metode mengajar yang dapat meningkatkan kemampuan spasial siswa dalam memanipulasi objek. Levenson (1995) juga mengatakan mentransformasi selembar kertas menjadi figur tiga dimensi merupakan latihan unik dalam meningkatkan pemikiran spasial.

Tuğrul dan Kavici (dikutip dalam Cakmak, 2009) mengatakan origami merupakan aktivitas yang didasari metode-metode belajar seperti metode cooperative learning, project base learning, creative learning, active learning, dan brain based learning. Origami melibatkan kegiatan mendengar, menonton, melihat, dan melakukan (Boakes, 2009). Dengan kata lain, dalam kegiatan origami, anak diajak untuk berpartisipasi aktif agar dapat membuat figur origami. Hal ini juga dibutuhkan dalam metode experiential learning. Yount (dalam Hedin, 2009) mengatakan dalam metode experiential learning, siswa berpartisipasi aktif dalam sebuah kegiatan. 
Experiential learning dilandasi oleh teori konstruktivisme (Bruning, Schraw, Norby, \& Ronning dikutip dalam Latipah, 2017). Dalam teori konstruktivisme, belajar lebih dari sekedar menerima dan memproses informasi yang disampaikan oleh pengajar atau buku teks. Dalam konstrukvisme, pembelajaran merupakan konstruksi pengetahuan yang bersifat aktif dan personal (De Kock, Sleegers, \& Voeten dikutip dalam Latipah, 2017).

Experiential learning telah banyak diterapkan di berbagai bidang studi. Dari analisis yang dilakukan terhadap 1.004 entri dalam bibliografi pembelajaran melalui pengalaman pada tahun 1999 (Kolb, Boyatzis, \& Mainemelis dikutip dalam Kolb \& Kolb, 2009) menunjukkan 207 penelitian dilakukan di bidang manajemen, 430 penelitian di bidang pendidikan, 104 penelitian di bidang ilmu informasi, 101 penelitian di bidang psikologi, 72 penelitian di bidang ilmu kedokteran, 63 penelitian di bidang ilmu perawat, 22 penelitian di bidang akuntansi, dan 5 penilitian di ilmu hukum.

Di Indonesia, experiential learning juga sudah diterapkan untuk mengukur berbagai hal. Sandjaja (2011) menerapkan experiential learning sebagai basis dalam pendidikan karakter untuk anak Sekolah Dasar di salah satu sekolah di Jawa Tengah. Istikomayanti, Suwono, dan Irawati (2016) juga menerapkan experiential learning untuk mengembangkan kemampuan literasi lingkungan pada anak Sekolah Menengah Pertama di Kota Batu, Malang. Selain diterapkan pada siswa Sekolah Dasar dan Sekolah Menengah, Latipah (2017) menerapkan experiential learning pada jenjang pendidikan yang lebih tinggi, yaiut mahasiswa. Latipah (2017) menerapkan experiential learning untuk mengukur regulasi diri belajar mahasiswa.

Penelitian mengenai pembelajaran melalui pengalaman terus meningkat dari tahun ke tahun. Pada tahun 2008, jumlah bibliografi mengenai pembelajaran melalui pengalaman pada tahun terdapat 2.453 entri (Kolb \& Kolb, 2009). Meskipun metode experiential learning lebih sering digunakan untuk melatih kemampuan sosial-emosional, Kelly (1997) berpendapat teori mengenai experiential learning juga dapat di integrasi kedalam metode pengajaran

\section{Rumusan Masalah}

Berdasarkan pemaparan di atas, rumusan masalah dalam penelitian ini adalah "Apakah intervensi origami berbasis experiential learning dapat meningkatkan kemampuan spasial anak usia dini di TK X?"

\section{METODE PENELITIAN}

\section{Partisipan}

Partisipan pada penelitian ini adalah siswa/siswi kelompok besar TK X. Partisipan penelitian dipilih berdasaarkan karakteristik: (a) Siswa/siswi berusia antara 5-6 tahun; (b) partisipan sedang menjalani pendidikan di kelas K2 TK X tahun ajaran 2017-2018. Jenis kelamin partisipan tidak menjadi karakteristik penentu karena kemampuan spasial dimiliki oleh kedua jenis kelamin. Partisipan pada penelitian ini berjumlah tiga orang yang ditentukan berdasarkan hasil pre-test yang diberikan kepada seluruh siswa kelas K2 TK X.

\section{Desain Penelitian}

Desain penelitian yang digunakan dalam penelitian ini adalah desain kuasi eksperimen. Metode kuasi eksperimen dapat membuktikan hubungan sebab akibat dan mampu memanipulasi dengan 
tepat satu atau lebih variabel yang diinginkan peneliti. Hal ini sesuai dengan tujuan peneliti, yaitu melihat efektivitas pemberian intervensi origami berbasis experiential learning terhadap kemampuan spasial anak Taman Kanak-Kanak.

Desain intervensi penelitian dirancang berdasarkan konsep experiential learning yang dikembangkan oleh Kolb (1984). Desain intervensi diadaptasi dan disesuaikan dengan kegiatan origami. Tujuan dirancangnya intervensi ini adalah agar partisipan penelitian mendapatkan pengalaman pembelajaran (experiential learning) melalui sesi-sesi origami. Pemberian Intervensi akan diberikan sebanyak 8 kali pertemuan. Pada setiap pertemuan, peneliti menetapkan kegiatan dan tujuan yang akan dicapai oleh partisipan.

\begin{abstract}
Alat Ukur
Alat ukur yang digunakan dalam penelitian ini berupa lembar observasi yang dibuat oleh peneliti berdasarkan komponen kemampuan spasial yang dikemukakan oleh Piaget dan Inhelder (1971). Peneliti mengadaptasi 6 komponen kemampun spasial yang dikemukakan oleh Piaget \& Inhelder (1971) menjadi 3 sub dimensi dalam kemampuan spasial, yaitu hubungan topologi, hubungan proyektif, dan rotasi mental. Untuk mengukur kemampuan spasial partisipan penelitian, peneliti membuat lembar observasi yang meminta partisipan untuk menyebutkan posisi benda, menyebutkan bentuk bangun datar, dan membuat lipatan menggunakan kertas. Kemampuan spasial partisipan akan diukur sebanyak dua kali, pre-test dan post-test menggunakan alat ukur yang sama.
\end{abstract}

\title{
3. HASIL DAN PEMBAHASAN
}

\section{Hasil Pre-Test}

Pada awal pengambilan data, peneliti mengukur kemampuan spasial seluruh siswa kelas K2A TK X sebanyak 15 orang. Pre-test dilakukan secara individual pada tanggal 5 Februari 2018, 8 Februari 2018, 12 Februari 2018 dan 15 Februari 2018. Pengambilan data dilakukan pada saat jam pelajaran berlangsung (pukul 11.15 - 11. 35) selama kurang lebih 5 menit untuk masingmasing siswa. Setelah proses pengambilan data selesai, peneliti mengolah dan menginterpretasikan data tersebut dan diperoleh 3 siswa yang menjadi partisipan penelitian. Ketiga siswa ini merupakan siswa dengan skor pre-test terrendah.

\section{Hasil Post-Test}

Pengambilan data post-test dilakukan setelah delapan kali intervensi diberikan. Sama seperti pengambilan data pre-test, pengambilan data post-test dilakukan secara individual, selama kurang lebih 5 menit terhadap masing-masing siswa. Pengambilan data post-test dilakukan pada tanggal 2 April 2018 (DE dan GE) dan tanggal 5 April 2018 (AR). Pengambilan data dilakukan pada saat jam pelajaran berlangsung (pukul 11.15 - 11. 35). Dilihat dari gambaran data yang diperoleh setelah dilakukan proses intervensi origami dan pengambilan data post-test terhadap tiga partisipan, didapati ketiga partisipan memiliki kemampuan hubungan spasial topologi yang rata-rata sesuai dengan anak sesuai dengan anak seusianya. Hal ini dilihat dari pemahaman partisipan mengenai posisi benda kanan, kiri, atas dan bawah dengan diri sendiri maupun orang lain sebagai acuan. Ketiga partisipan juga memiliki kemampuan hubungan proyektif yang sesuai dengan anak seusianya dalam mengenal bentuk bangun datar dasar (persegi, persegi panjang, segitiga, dan lingkaran). Hasil post-test dari ketiga partisipan dapat dilihat pada tabel 2. 


\section{Tabel 1.}

\section{Hasil post-test}

\begin{tabular}{|c|c|c|c|}
\hline Item & De & $\mathbf{A r}$ & Ge \\
\hline $\begin{array}{l}\text { Menyebutkan posisi benda di sekitar dengan diri sendiri sebagai acuan (benda berada di sebelah } \\
\text { kanan) }\end{array}$ & $\checkmark$ & $\checkmark$ & $\checkmark$ \\
\hline $\begin{array}{l}\text { Menyebutkan posisi benda di sekitar dengan diri sendiri sebagai acuan (benda berada di sebelah } \\
\text { kiri) }\end{array}$ & $\checkmark$ & $\checkmark$ & $\checkmark$ \\
\hline $\begin{array}{l}\text { Menyebutkan posisi benda di sekitar dengan benda lain sebagai acuan (benda berada di sebelah } \\
\text { kanan) }\end{array}$ & $X$ & $\checkmark$ & $\checkmark$ \\
\hline $\begin{array}{l}\text { Menyebutkan posisi benda di sekitar dengan benda lain sebagai acuan (benda berada di sebelah } \\
\text { kiri) }\end{array}$ & $\mathrm{X}$ & $\checkmark$ & $\checkmark$ \\
\hline Menyebutkan posisi benda di sekitar dengan benda lain sebagai acuan (benda berada di atas) & $\checkmark$ & $\checkmark$ & $\checkmark$ \\
\hline Menyebutkan posisi benda di sekitar dengan benda lain sebagai acuan (benda berada di bawah) & $\checkmark$ & $\checkmark$ & $\checkmark$ \\
\hline Menyebut bentuk geometri: persegi & $\checkmark$ & $\checkmark$ & $\checkmark$ \\
\hline Menyebut bentuk geometri: persegi panjang & $\checkmark$ & $\checkmark$ & $\checkmark$ \\
\hline Menyebut bentuk geometri: segitiga & $\checkmark$ & $\checkmark$ & $\checkmark$ \\
\hline Menyebut bentuk geometri: lingkaran & $\checkmark$ & $\checkmark$ & $\checkmark$ \\
\hline Melipat kertas bentuk persegi menjadi persegi panjang & $\checkmark$ & $\checkmark$ & $\mathrm{X}$ \\
\hline Melipat kertas bentuk persegi menjadi segitiga & $\checkmark$ & $\checkmark$ & $\checkmark$ \\
\hline Melipat kertas bentuk persegi panjang menjadi persegi & $\checkmark$ & $\mathrm{X}$ & $\mathrm{X}$ \\
\hline Total & 11 & 12 & 11 \\
\hline
\end{tabular}

\section{Pembahasan}

Dari data yang didapatkan peneliti setelah melakukan proses intervensi origami terhadap 3 partisipan, didapatkan beberapa hal sebagai berikut. Ketiga partisipan mengalami peningkatan kemampuan dalam ketiga sub dimensi dari kemampuan spasial. GE dan AR juga mengalami peningkatan kemampuan hubungan proyektif dalam hal mengenal bentuk bangun datar dari berbadai sudut pandang. Ketiga partisipan juga mengalami peningkatan kemampuan rotasi mental dalam membayangkan perubahan sebuah objek dengan cara melipat kertas. Perbandingan skor pre-test dan post-test ketiga partisipan dapat dilihat pada tabel 23 .

\section{Tabel 2}

Perbandingan skor pre-test dan post-test ke 3 Partisipan

\begin{tabular}{|c|c|c|c|c|c|c|}
\hline \multirow[b]{2}{*}{ Item } & \multicolumn{2}{|c|}{ DE } & \multicolumn{2}{|c|}{$\mathbf{A R}$} & \multicolumn{2}{|c|}{ GE } \\
\hline & $\begin{array}{c}\text { Pre - } \\
\text { test }\end{array}$ & $\begin{array}{c}\text { Post - } \\
\text { test }\end{array}$ & $\begin{array}{c}\text { Pre - } \\
\text { test }\end{array}$ & $\begin{array}{c}\text { Post - } \\
\text { test }\end{array}$ & $\begin{array}{c}\text { Pre - } \\
\text { test }\end{array}$ & $\begin{array}{c}\text { Post - } \\
\text { test }\end{array}$ \\
\hline $\begin{array}{l}\text { Menyebutkan posisi benda di sekitar dengan } \\
\text { diri sendiri sebagai acuan (benda berada di } \\
\text { sebelah kanan) }\end{array}$ & $\checkmark$ & $\checkmark$ & $\checkmark$ & $\checkmark$ & $\mathrm{X}$ & $\checkmark$ \\
\hline $\begin{array}{l}\text { Menyebutkan posisi benda di sekitar dengan } \\
\text { diri sendiri sebagai acuan (benda berada di } \\
\text { sebelah kiri) }\end{array}$ & $\checkmark$ & $\checkmark$ & $\checkmark$ & $\checkmark$ & $\mathrm{X}$ & $\checkmark$ \\
\hline Menyebutkan posisi benda di sekitar dengan & $\checkmark$ & $\checkmark$ & $\checkmark$ & $\checkmark$ & $\checkmark$ & $\checkmark$ \\
\hline
\end{tabular}


benda lain sebagai acuan (benda berada di atas)

Menyebut bentuk geometri: persegi

Menyebut bentuk geometri: persegi panjang

Menyebut bentuk geometri: segitiga

Menyebut bentuk geometri: lingkaran

Melipat kertas bentuk persegi menjadi persegi panjang

\begin{tabular}{llllll}
$\checkmark$ & $\checkmark$ & $\checkmark$ & $\checkmark$ & X & $\checkmark$ \\
$\checkmark$ & $\checkmark$ & $\checkmark$ & $\checkmark$ & $\checkmark$ & $\checkmark$ \\
$\checkmark$ & $\checkmark$ & X & $\checkmark$ & X & $\checkmark$ \\
$\checkmark$ & $\checkmark$ & $\checkmark$ & $\checkmark$ & $\checkmark$ & $\checkmark$ \\
$\checkmark$ & $\checkmark$ & X & $\checkmark$ & X & X \\
X & $\checkmark$ & X & $\checkmark$ & X & $\checkmark$ \\
X & $\checkmark$ & X & X & X & X \\
\hline 9 & 11 & 9 & 12 & 4 & 11 \\
\hline
\end{tabular}

Melipat kertas bentuk persegi menjadi segitiga

Melipat kertas bentuk persegi panjang menjadi persegi

Total 9

Dibandingkan dengan penelitian-penelitian yang telah dilakukan, terdapat beberapa hal yang dapat dijadikan bahan perbandingan. Hasil penelitian menunjukkan intervensi origami berbasis experiential learning meningkatkan kemampuan spasial anak anak usia dini. Hal ini sesuai dengan penjelasan Tambunan (2006) mengenai kemampuan spasial yang memerlukan pemahaman tata letak, pemahaman perspektif, bentuk-bentuk geometris, dan kemampuan dalam transformasi mental dari bayangan visual. Keempat pemahaman ini merupakan pemahamanpemahaman yang diperlukan anak dalam membuat figur origami. Ketika membuat figur origami, anak memerlukan pemahaman tata letak untuk mengetahui titik awal lipatan. Instruksi origami yang dilihat anak melatih kemampuan anak dalam memahami tata letak dan kemampuan untuk melakukan transformasi mental melalui bayangan visual.

Meskipun experiential learning lebih banyak diterapkan pada jenjang pendidikan yang lebih tinggi, data hasil post-test menunjukkan experiential learning dapat juga diterapkan pada anak usia dini. Hal ini mungkin saja terjadi karena selama proses intervensi berlansung, anak mendapat pengarahan yang memadai. Vygotsky mengatakan pengaruh sosial, terutama instruksi, penting dalam perkembangan kognitif anak (Santrock, 2011). Vygotsky mengemukakan setiap anak memiliki batas yang berbeda dalam menguasai sebuah kemampuan, yang dikenal sebagai ZPD atau zone of proximal development (Santrock, 2011).

Vygotsky menjelaskan ZPD sebagai batas kesulitan dari sebuah tugas atau kemampuan yang tidak dapat dikuasai anak seorang diri. Namun anak dapat menguasai tugas atau kemampuan ini dengan bantuan dan pengarahan dari orang dewasa atau anak lain yang lebih menguasai tugas atau kemampuan tersebut. Scaffolding merupakan teknik yang digunakan untuk membantu anak mempelajari suatu kemampuan atau tugas. Melalui scaffolding, guru atau anak yang lebih menguasai kemampuan tertentu membantu anak lain dengan memberikan pengarahan yang sesuai dengan kemampuan anak tersebut. Selama proses intervensi, partisipan penelitian mendapatkan pengarahan dan bimbingan langsung dari peneliti sehingga pada akhir proses intervensi, kemampuan spasial partisipan mengalami peningkatan. Tidak hanya peneliti, partisipan lain yang lebih menguasai lipatan origami terlebih dahulu juga membantu partisipan yang kurang menguasai. Sehingga ketiga partisipan pada akhir sesi intervensi dapat membuat origami sesuai dengan instruksi yang diberikan.Hal ini menunjukkan scaffolding juga turut berperan dalam proses intervensi pada penelitian ini. 
Hal lain yang juga dijadikan diskusi dari penelitian ini adalah batasan umur dalam kegiatan origami. Berdasarkan observasi yang dilakukan peneliti selama proses intervensi berlangsung, ketiga partisipan yang masih berusia 5 tahun dapat membuat figur origami dengan mengikuti instruksi yang diberikan. Hal ini tidak sesuai dengan pernyataan Temko (2003). Temko mengatakan idealnya origami mulai diajarkan saat anak berusia 7 tahun karena pada usia tersebut koordinasi mata-tangan anak mulai berkembang dengan baik.

Data hasil post-test menunjukkan kemampuan spasial ketiga partisipan mengalami peningkatan. Disamping kemampuan spasial, partisipan juga menjadi lebih peka terhadap satu sama lain. Levenson (1995) mengemukakan, selain melatih kemampuan spasial, oigami juga dapat melatih aspek lain dalam perkembangan anak, salah satunya melatih cooperative learning. Levenson menambahkan kegiatan melipat kertas cenderung mengurangi status yang diasosiasikan dengan umur. Anak yang lebih kecil seringkali mengajari anak yang lebih tua. Anak-anak ini kemudian dapat membantu teman-teman sekelasnya untuk menguasai langkah-langkah origami. Hal ini sejalan dengan observasi peneliti terhadap partisipan saat intervensi berlangsung. DE merupakan partisipan pertama yang menguasai cara melipat origami dengan baik. Ketika DE melihat kedua temannya kesulitan dalam memahami instruksi origami yang diberikan, DE menyemangati dan mengajarkan temannya untuk membuat lipatan-lipatan figur origami yang harus dibuat.

Di sisi lain, peneliti juga mengakui keterbatasan yang muncul dalam penelitian ini. Penelitian ini hanya dilakukan pada satu kelompok subyek. Dimana tiga partisipan yang dijadikan subyek penelitian diberikan intervensi tanpa adanya pembandingan dari kelompok lain untuk dijadikan data kontrol. Maka dari itu peneliti tidak dapat melakukan kontrol terhadap perkembangan yang dialami oleh ketiga subyek partisipan. Partisipan yang terlibat dalam penelitian ini juga hanya tiga orang. Hal ini juga merupakan kelemahan dalam penelitian ini karena jumlah partisipan yang terlalu sedikit sehingga hasil penelitian kurang dapat digeneralisasikan.

Intervensi pada penelitian ini juga diberikan langsung oleh peneliti. Peneliti sendiri yang mengumpulkan data pre-test dan post-test, serta memberikan intervensi. Hal ini juga menjadi kelemahan dalam penelitian ini karena dalam penelitian ini tidak terdapat interpreter yang mengawasi berlangsungnya proses penelitian (dari pre-test hingga post-test). Dengan tidak adanya interpreter maka memungkinkan terjadinya bias experimenter. Peneliti juga mengakui kelemahan dalam alat ukur yang digunakan dalam peneltian ini. Peneliti membuat sendiri alat ukur berupa lembar observasi untuk mengambil data pre-test dan post-test. Hal ini menyebabkan validitas dan reliabilitas alat ukur yang digunakan dalam penelitian ini kurang meyakinkan.

\section{KESIMPULAN DAN SARAN}

\section{Kesimpulan}

Ketiga partisipan mengalami peningkatan dalam kemampuan spasial setelah mengikuti proses intervensi origami sebanyak 8 kali pertemuan. Meskipun mengalami peningkatan dalam kemampuan spasial, ketiga partisipan mengalami peningkatan dalam dimensi yang berbeda. Dari ketiga partisipan, hanya GE yang mengalami peningkatan dalam dimensi hubungan spasial topologi (mengetahui posisi objek dengan diri sendiri maupun benda lain sebagai acuan).

GE dan AR juga mengalami peningkatan dalam dimensi hubungan proyektif. Keduanya mampu mengenali keempat bentuk bangun datar yang diperlihatkan pada saat pengambilan data posttest. Sebelumnya, GE hanya mengenali 2 bentuk dan AR mengenali 3 bentuk. Dalam dimensi rotasi mental, ketiga partisipan mengalami peningkatan. DE mampu melipat kertas menjadi tiga 
macam bentuk bangun datar, AR mampu melipat kertas menjadi dua macam bentuk bangun datar, sedangkan GE mampu melipat kertas menjadi satu macam bentuk bangun datar.

\section{Saran}

Dari hasil penelitian yang dilakukan peneliti terhadap peningkatan kemampuan spasial melalui kegiatan origami, peneliti menyarankan penelitian selanjutnya untuk melakukan penelitian serupa pada tingkat kelas yang lebih rendah, misalnya untuk anak TK A. Hal ini dikarenakan kegiatan origami tidak hanya melibatkan aspek spasial dalam rotasi mental, namun juga melibatkan aspek motorik halus, khususnya dalam melipat kertas.

Peneliti juga menyarankan penelitian selanjutnya untuk membuat kelompok kontrol agar hasil penelitian lebih maksimal dan membuat kelompok perlakuan (partisipan) yang lebih besar. Peneliti menyarankan hal ini agar hasil penelitian dapat digeneralisasikan.

Melalui hasil penelitian yang telah dilakukan, peneliti menyarankan pihak sekolah agar dapat menggunakan kegiatan origami sebagai salah satu sarana pembelajaran di dunia pendidikan. Kegiatan origami dapat dilakukan baik untuk mendukung materi pembelajaran di sekolah, maupun aktivitas diluar kegiatan belajar-mengajar.

Peneliti juga menyarankan orangtua yang memiliki anak usia dini untuk menyediakan, memperkenalkan, dan mengajak anak untuk mengisi waktu luang dengan kegiatan origami dibandingkan bermain dengan gadget. Melalui kegiatan origami, anak tidak hanya melakukan kegiatan satu arah. Kegiatan origami juga dapat diterapkan sebagai kegiatan antar usia, dengan demikian peneliti menyarankan orangtua untuk dapat menjadikan origami sebagai kegiatan hiburan di tengah anggota keluarga.

\section{Ucapan Terima Kasih}

Peneliti mengucapkan terima kasih kepada kepala sekolah TK X dan guru kelas K2A, serta siswa/siswi yang telah terlibat dalam penelitian ini. Terima kasih kepada TK $X$ yang telah memberikan kesempatan, kepercayaan dan dukungan penuh kepada peneliti untuk melaksanakan intervensi origami di TK X.

\section{REFERENSI}

Anita, A., Risyak, B., \& Surahman, M. (2016). Implementasi bermain balok unit dalam meningkatkan kecerdasan visual spasial anak usia dini. Jurnal Pendidikan Anak, 1(6).6-12

Boakes, N. J. (2009). Origami instruction in the middle school mathematics classroom: Its impact on spatial visualization and geometry knowledge of students. RMLE Online, 32(7), $1-12$.

Casey, M. B., Nuttall, R. L., \& Pezaris, E. (2001). Spatial-mechanical reasoning skills versus mathematics self-confidence as mediators of gender differences on mathematics subtests using cross-national gender-based items. Journal for Research in Mathematics Education, 32(1), 28-57.

Cakmak, S. (2009). An investigation of the effect of origami-based instruction on elementary students' spatial ability in mathematics. Unpublished master's thesis, Orta Doğu Teknik Üniversitesi, Sosyal Bilimler Enstitüiü, Ankara. 
Cakmak, S., Isiksal, M., \& Koc, Y. (2014). Investigating effect of origami-based instruction on elementary students' spatial skills and perceptions. The Journal of Educational Research, 107(1), 59-68.

Cheng, Y. L., \& Mix, K. S. (2014). Spatial training improves children's mathematics ability. Journal of Cognition and Development, 15(1), 2-11.

Delgado, A. R., \& Prieto, G. (2004). Cognitive mediators and sex-related differences in mathematics. Intelligence, 32(1), 25-32.

Duncan, G. J., Dowsett, C. J., Claessens, A., Magnuson, K., Huston, A. C., Klebanov, P., ... \& Sexton, H. (2007). School readiness and later achievement. Developmental psychology, 43(6), 1428.

Geary, D. C., Hoard, M. K., Byrd-Craven, J., Nugent, L., \& Numtee, C. (2007). Cognitive mechanisms underlying achievement deficits in children with mathematical learning disability. Child development, 78(4), 1343-1359.

Hedin, N. (2010). Experiential learning: theory and challenges. Christian Education Journal, 7(1), 107.

Holmes, J., Adams, J. W., \& Hamilton, C. J. (2008). The relationship between visuospatial sketchpad capacity and children's mathematical skills. European Journal of Cognitive Psychology, 20(2), 272-289.

Jordan, N. C., Kaplan, D., Ramineni, C., \& Locuniak, M. N. (2009). Early math matters: kindergarten number competence and later mathematics outcomes. Developmental psychology, 45(3), 850.

Juli, S. P., Saparahayuningsih, S., \& Suprapti, A. (2014). Meningkatkan kecerdasan visualspasial anak usia dini dengan metode bermain building g-blok pada kelompok b6 di taman kanak-kanak dharma wanita persatuan provinsi bengkulu(Doctoral dissertation, Universitas Bengkulu).

Klibanoff, R. S., Levine, S. C., Huttenlocher, J., Vasilyeva, M., \& Hedges, L. V. (2006). Preschool children's mathematical knowledge: The effect of teacher" math talk.". Developmental psychology, 42(1), 59.

Kolb, D. (1984). Experiential learning: experience as the source of learning \& development. Englewood Cliffs, NJ: Prentice-Hall.

Latipah, E. (2017). Pengaruh Strategi Experiential Learning Terhadap Self Regulated Learning Mahasiswa. Humanitas: Jurnal Psikologi Indonesia, 14(1), 41-56.

Levenson, G. (1995). The educational benefits of origami. Diunduh dari http://home.earthlink.net/ robertcubie/origami/edu.html

McKenzie, B., Bull, R., \& Gray, C. (2003). The effects of phonological and visual-spatial interference on children's arithmetical performance. Educational and Child Psychology, 20(3), 93-108.

Olkun, S. (2003). Making connections: Improving spatial abilities with engineering drawing activities. International Journal of Mathematics Teaching and Learning, 3(1), 1-10.

Piaget, J., \& Inhelder, B. (1971). Mental imagery in the child; a study of the development of imaginal representation (PA Chilton, Trans.). New York: Basic.(Original work published 1966).

Rasmussen, C., \& Bisanz, J. (2005). Representation and working memory in early arithmetic. Journal of experimental child psychology, 91(2), 137-157.

Starkey, P., Klein, A., \& Wakeley, A. (2004). Enhancing young children's mathematical knowledge through a pre-kindergarten mathematics intervention. Early Childhood Research Quarterly, 19(1), 99-120.

Temko, F. (2003). Origami toys. Singapore: Turtle Publishing. 
TUĞRUL, B., \& KAVICI, M. (2002). PAPER FOLDING ART ORIGAMI AND LEARNING. Pamukkale University Education Faculty Journal , 11 (11), 1-17.

Wijayaningsih, L., \& Agnesi, Y. W. (2014). Upaya meningkatkan kemampuan visual spasial anak untuk mengenal bentuk melalui media papan geometri dari flannel di kelompok a di tk pertiwi purworejo 1. Diunduh dari http://www.widyasaripress.com/index.php?option=com_content $\&$ view=article\&id=438:upaya-meningkatkankemampuan-visual-spasial-anak-untuk-mengenal-bentuk\&catid=65:vol-17-no-4september-2015-seri-ii 